\title{
Arsenic Oxyanions Removal from Waste Water by Accelerated Carbonation*
}

\author{
by Thenepalli THRIVENI ${ }^{\mathrm{a}}$, Ji Whan $\mathrm{AHN}^{\mathrm{a}^{*}}$ and Chilakala RAMAKRISNA ${ }^{\mathrm{b}}$
}

\begin{abstract}
Currently, arsenic contamination in drinking water is an emerging issue around the world. Arsenic contamination is severe threat to the environment and human beings. Several researchers and organizations standardized the arsenic levels in drinking water. This research focuses on the effect of accelerated carbonation process for successful removal of heavy metal arsenic anions from artificial waste water and we applied this technology was going to be apply to the real waste waters. This accelerated carbonation process is a simple, economic and ecofriendly process with $85 \sim 88 \%$ removal efficiency and also it improves immobilization of solidified/stabilized the heavy metals.
\end{abstract}

KEY WORDS: Arsenic Oxyanions, Removal, Waste Water, Carbonation

\section{Introduction}

Since, two or three decades, arsenic contamination is an emerging global issue. New modern water treatment technologies required for arsenic removal from waste waters contaminated extensively by various background sources. Arsenic concentration limits in drinking water limit of $10 \mu \mathrm{g}$ $\mathrm{L}^{-1}$ by U.S. Environmental Protection Agency (EPA) and the World Health Organization (WHO). ${ }^{1,2)}$ Still, 100 million people are the sufferers with the arsenic contamination from various resources. $^{3,4)}$ throughout the world (both South, South East Asian countries and USA. ${ }^{5)}$ As per the state of art, there are wide variety of treatment methodologies are available for the removal of arsenic from waste water and drinking water. ${ }^{6)}$ Among those conventional methods, the carbonation process ${ }^{7)}$ is more convenient, economic and eco-friendly process. National Pollution Discharge Elimination System (NPDES) program controls the arsenic discharge levels. Recently, some power plants in the United States have been limited to arsenic discharges daily maximum $4 \mu \mathrm{g} / \mathrm{L} .{ }^{8)}$ Some researchers reported an innovative As removal and recovery technologies were used for arsenic from wastewater using metal complexes such as $\mathrm{TiO}_{2}$ and zirconium polyacrylamide ( $\left.\mathrm{ZrPACM}-43\right)^{9)}$ super paramagnetic $\mathrm{Fe}_{3} \mathrm{O}_{4}$ nanoparticles ${ }^{10)}$, Mn-incorporated iron (III) oxide nano particles ${ }^{11)}$, graphite oxide modified composites $^{12)}$ and Hydrous zirconium oxide (HZO)-originated nanocomposite. $^{13)}$

Biosorption of As(III) by L.acidophilus was used for the removal of As(III) from As(III)-containing water solution. ${ }^{14)}$

Aquatic booster as adsorbent can used for boron and arsenic removal from waste water generated by petrochemical industries. ${ }^{15)}$ Arsenic removal from groundwater under anaerobic conditions by in situ treatment by air sparging and arsenic removal by co-precipitation (iron/arsenic). ${ }^{16)}$

As per state of art, many researchers investigated

*Received 16 June, 2016; accepted for publication 25 November, 2016

a. Mineral Processing Division, Korea Institute of Geosciences and Mineral Resources

(KIGAM), Yuseong-gu, Daejeon, 305350, Korea

(*Corresponding author, E-mail: ahnjw@kigam.re.kr)

b. Department of R\&D Team, Hanil Cement Corporation, Danyang, 395-903, Korea absorption process of arsenic removal from drinking water. Some researchers reported the artificial neural network model for reasonable predictive performance of arsenic adsorption process. ${ }^{17)}$

Combined electrocoagulation and microfiltration approach for the removal of arsenic from drinking water was successfully investigated by continuous mode operation. ${ }^{18)}$

Many technical reports and papers published compare mitigation options ${ }^{19)}$ but process analysis method (PAM) can be applied to assess the sustainability of mitigation options for arsenic in drinking water. ${ }^{20)}$

The aim of this research is removal of arsenic oxy anions from the synthetic waste water by accelerated carbonation process.

\section{Experimental Procedure}

\section{$2 \cdot 1$ Process and materials}

The removal of arsenic is formed carbonate by a carbonation method in which gaseous $\mathrm{CO}_{2}$ in injected into a $\mathrm{Ca}^{2+}$ ion solution with $\mathrm{As}^{5+} \cdot 0.2 \mathrm{M} \mathrm{Ca}(\mathrm{OH})_{2}$ (Calcium hydroxide, $95 \%$, Junsei, Japan) solution was prepared in a 1 $\mathrm{L}$ glass reactor, using commercial calcium hydroxide and 48.7 mg of $\mathrm{Na}_{2} \mathrm{HAsO}_{4} \cdot 7 \mathrm{H}_{2} \mathrm{O}$ (Sodium acid arsenate heptahydrate, $98 \%$ purity) was transferred into $15 \mathrm{~g} / \mathrm{L} \mathrm{Ca}(\mathrm{OH})_{2}$ solution. $\mathrm{Ca}(\mathrm{OH})_{2}$ solution with arsenic oxyanion was then slightly heated to $30^{\circ} \mathrm{C}$ using an oven specifically adapted to the reactor. When the dispersion temperature was stabilized then 20 bar of $\mathrm{CO}_{2}$ was bubbled into the reactor. The stirring speed was $400 \mathrm{rpm}$ and the total reaction time was $1 \mathrm{~h} 20 \mathrm{~min}$. The apparatus for arsenic removal by accelerated carbonation presented in Fig. 1 (a) shows schematic experimental system for arsenic removal and (b)shows the flowsheet of experimental procedure.

\section{Results and Discussions}

In this work, we checked the possibility of removal of arsenic by carbonation process. Fig. 2 shows XRD result of formed calcium carbonate (Calcite) from $\mathrm{Ca}(\mathrm{OH})_{2}$ solution with reacted $\mathrm{CO}_{2}$ and it means to revealed a complete $\mathrm{Ca}(\mathrm{OH})_{2}$ - 


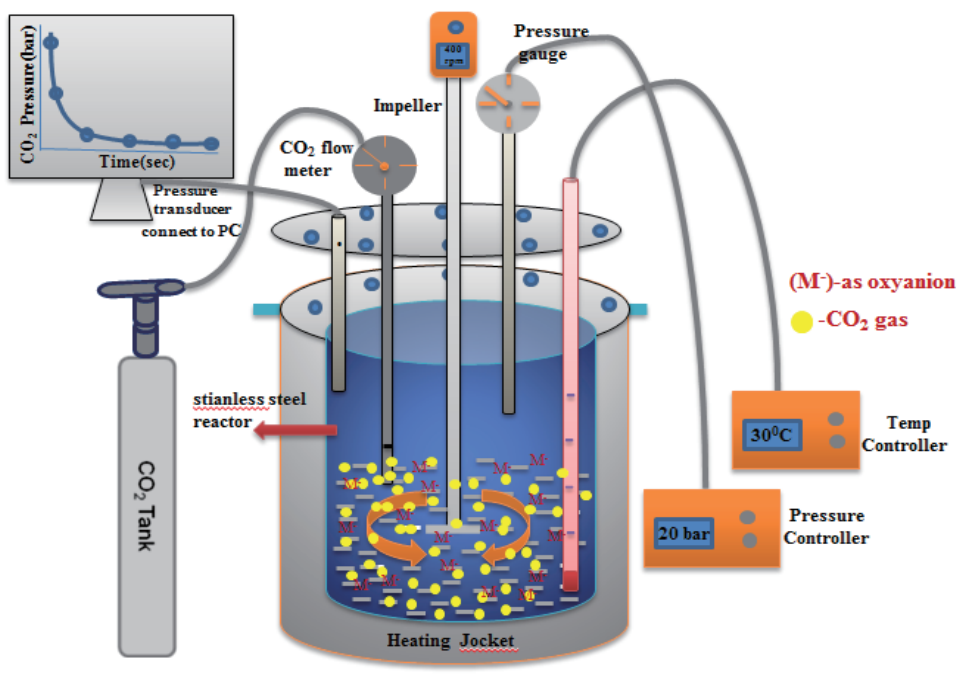

(a)

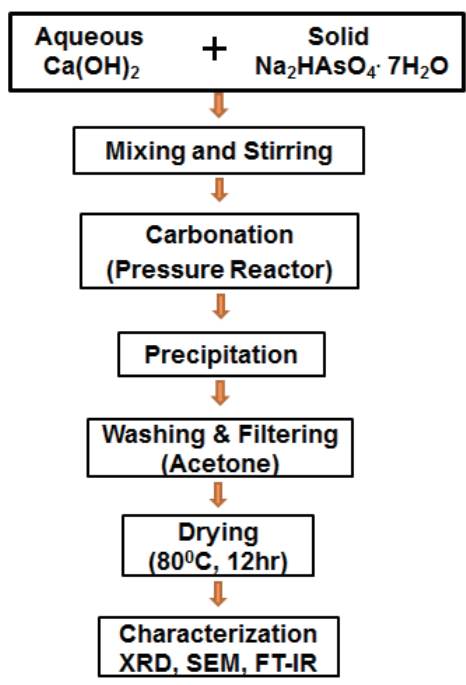

(b)

Fig.1 (a) Apparatus of arsenic removal by accelerated carbonation process. (b) Flowsheet of the carbonation procedure.

calcium carbonate transformation for all calcium hydroxide carbonation experiment. Fig. 3 shows FT-IR result of the experiment, it has a complete transformation of all calcium hydroxide $\left(\mathrm{Ca}(\mathrm{OH})_{2}\right)$ into calcium carbonate $\left(\mathrm{CaCO}_{3}\right)$ and its carbonation reaction allowed the removal of arsenate oxyanion. The presence of oxyanions could The $\mathrm{OH}$-stretching vibration band (1) at $3642 \mathrm{~cm}^{-1}$ corresponding to the calcium hydroxide, was not detected in the solid product. Here, the $\mathrm{CO}_{3}$ stretching vibration band (2) at $1410-1490 \mathrm{~cm}^{-1}$ and the $\mathrm{CO}_{3}$ - bending vibration band at $877 \mathrm{~cm}^{-1}$ are typical fundamental bands for calcite. The obtained solid product was characterized through XRD, FT-IR and scanning electron microscopy (SEM). XRD analysis showed the pure calcium carbonate (Calcite).

Morphological analysis of calcite samples were performed by Scanning Electron Microscopy (SEM) showed in Fig. 4, and it showed that the calcite products via $\mathrm{Ca}(\mathrm{OH})_{2}$ carbonation without or with dissolved oxyanions. C-axis stretching of calcite was clearly observed in the presence of arsenate.

The removal efficiency of arsenate using $\mathrm{Ca}(\mathrm{OH})_{2}$ carbonation with compressed $\mathrm{CO}_{2}$, it was calculated using followed equation.

$$
\text { Removal (\%) }=\mathrm{C}_{0}-\mathrm{C}_{\mathrm{e}} / \mathrm{C}_{0} \text { X } 100
$$

Where, $\mathrm{C}_{0}$ and $\mathrm{C}_{\mathrm{e}}[\mathrm{g} / \mathrm{L}]$ are the initial concentration of arsenic oxyanion and the concentration of oxyanion at the equilibrium respectively. The carbonation reaction using about $15 \mathrm{~g} / \mathrm{L}$ of commercial $\mathrm{Ca}(\mathrm{OH})_{2}$ successfully removed arsenate $(>85 \%$ ) from the synthetic solutions (Fig. 5). At $10 \mathrm{~g} / \mathrm{L}$ dose of $\mathrm{Ca}(\mathrm{OH})_{2}$, the removal efficiency was not influenced by the initial concentration for arsenate. Conversely, the removal efficiency increased significantly maximum $88 \%$ for arsenate when a dose of $15 \mathrm{~g} / \mathrm{L} \mathrm{Ca}(\mathrm{OH})_{2}$ was used.

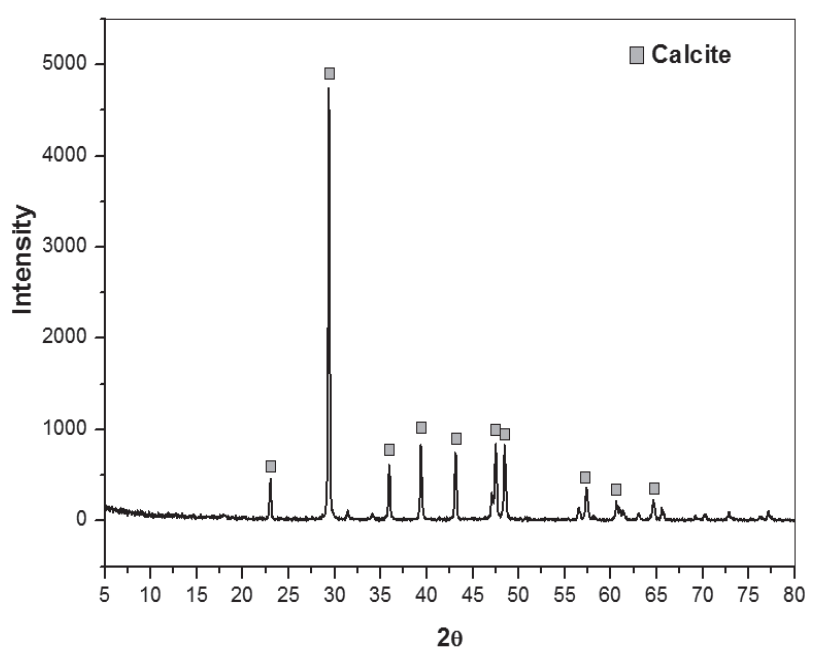

Fig.2 XRD analysis of Calcite.

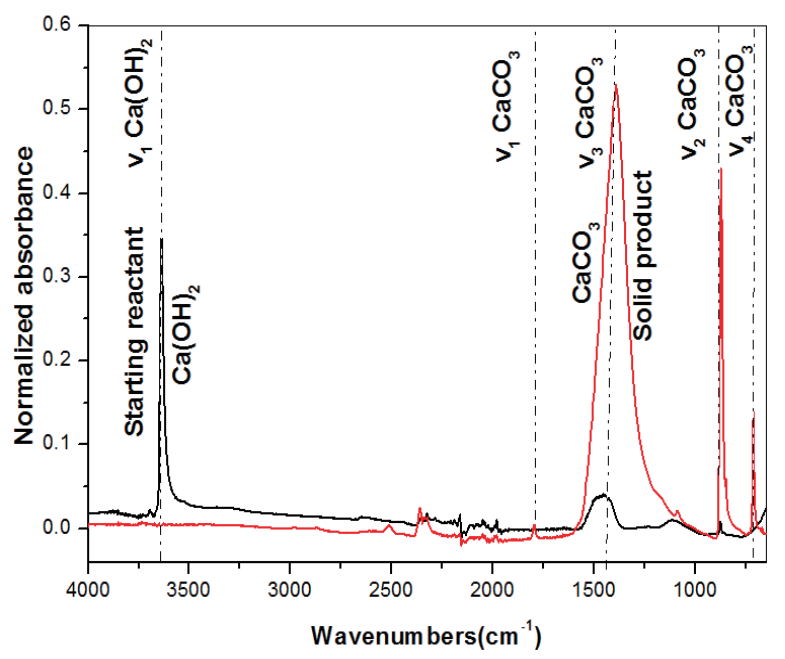

Fig.3 FT-IR result of calcium carbonate (calcite). 


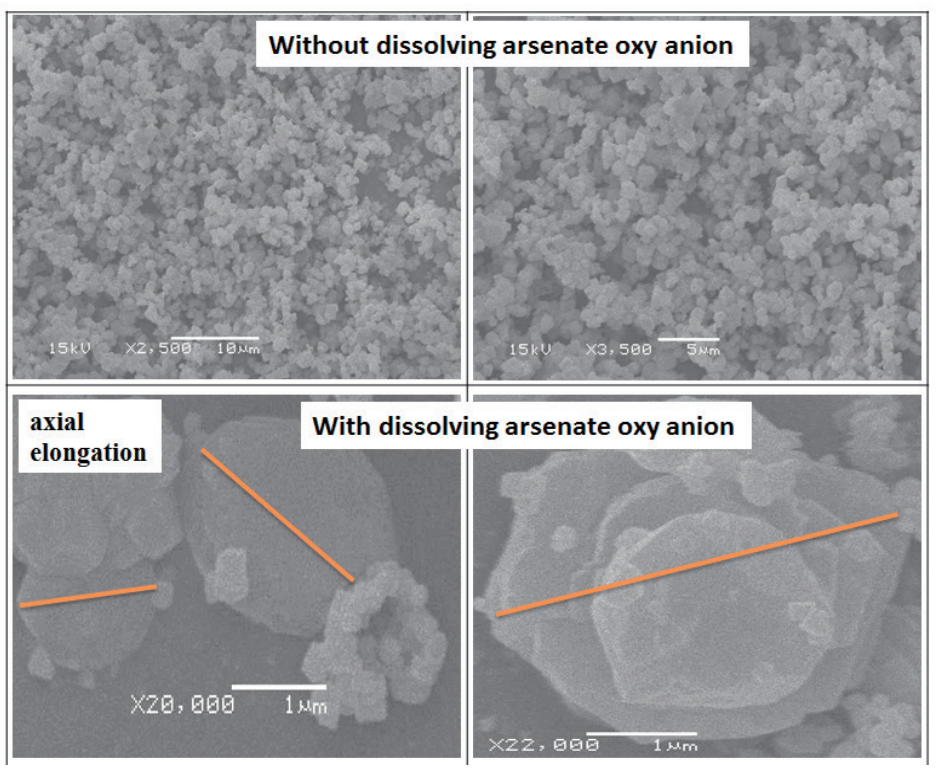

Fig.4 SEM analysis of calcium carbonate (calcite).

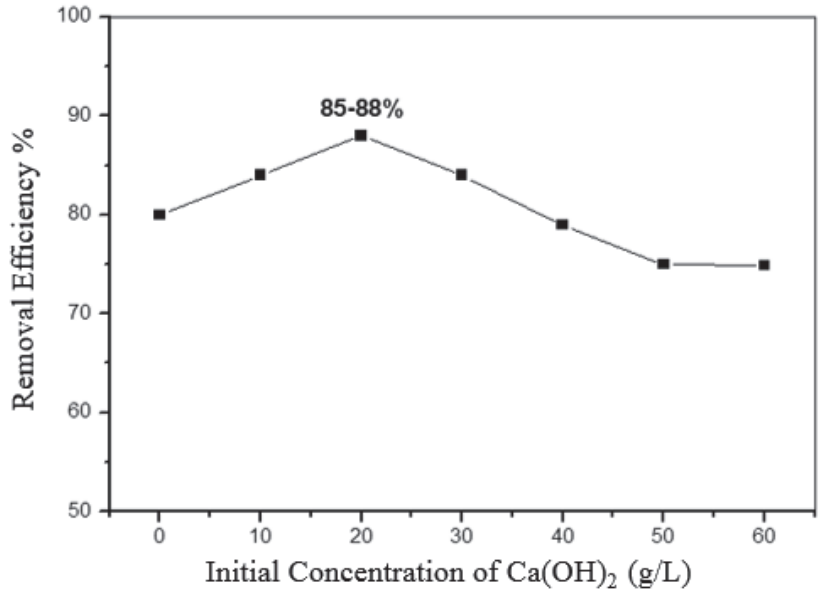

Fig.5 Removal efficiency of arsenate by carbonation with compressed $\mathrm{CO}_{2}$.

\section{Conclusion}

In this study, the main purpose was to investigate the removal of oxyanions from an aqueous solution of calcium hydroxide using carbonation under moderate pressure at $30 \mathrm{bar}$ and temperature at $30^{\circ} \mathrm{C}$. It was demonstrated that the $\mathrm{Ca}(\mathrm{OH})_{2}$ carbonation allows successfully the removal of arsenate (85$88 \%$ ) from synthetic solutions. Removal of arsenic oxyanions from original mine waste waters is ongoing

Acknowledgments The authors are very grateful to the Korea Institute of Energy Technology Evaluation and Planning through the ETI program, Ministry of Trade, Industry and Energy (Project No. 2013T100100021) for financial support of this research.

\section{References}

1) D.Mohan and C.U. Pittman: J. Haz. Mater, 142 (2007) 1-53.

2) Exposure to arsenic: A major public health concern. Preventing disease through healthy environments, World Health Organization (WHO), (2010), 1.

3) E. Sohn: Nature, 514 (2014) S62-3.

4) B.Yudhijit: Science, 315 (2007) 1659-1661

5) G.Vaidyanathan: Nature News, (2011) 1.

6) H.Liu, K.C. Zuo and C.D.Vecitis: Environ. Sci. Technol, 48 (2014) 13871-13879.

7) G.M.Hernandez, N. Concha Ozano, F. Renard and E. Quirico: J. Haz. Mater, 166 (2009) 788-795.

8) News, EPA Continues to Tighten Environmental Regulations for Coal Fired Power Plants, Exponent Engineering and Scientific Consulting, Oct.2015.

9) Ting Luo, Jinlicui, Shanhu, Yuyinghuang and Chuanyongjing: Environ. Sci. Technol, 44 (2010) 9094-9098.

10) L.Sneha, S.Shripal and S.Amalendu: J. Magnet. Magnet. Mate, 356 (2014) 21-31.

11) Abir Ghosh, Sharadindra Chakrabarti and Uday Chand Ghosh: Chemical Engineering J, 248 (2014) 18-26.

12) Can Wang, Hanjin Luo, Zilong Zhang, Yan Wu, Jian Zhang and Shaowei Chen: J. of Hazardous Materials, 268 (2014) 124-131.

13) B. Pan, Z. Li, Y. Zhang, J. Xu, L. Chen, H. Dong and W. Zhang: Chem. Eng. J, 248 (2014) 290-296.

14) S. Asha Lata and P. N. Sarma: Bioremed. J. 14 (2010) 92-97.

15) M. H. S. Ismail, X. T. Zhang, M. F. M. Lazim: J. Environ. Stu. 22 (2013), 403.

16) J. H. Brunsting, E. A. McBean, Contami. Hydro. 159 (2014), 20-35.

17) P. Roy, N. K. Mondal, K. Das: J. Environ. Chem. Eng. 2 (2014), 585-597.

18) C. C. Molgora, A. M. Dominguez, E. M. Avila, P. Drogui, G. Buelna: Sepa. Purif. Tech. 118 (2013), 645-651.

19) C. K. Jain, R. D. Singh: J. Environ. Manag. 107 (2012), 1-18

20) T. R. Etmannski, R. C. Darton: Sci. Total. Environ. 488 (2014), 505-511. 